\title{
Desarrollo profesional y formación docente online. El caso de "Mini- Deportistas", un proyecto de música y movimiento
}

Ana Quílez Ibáñez - Universidad de Girona

Miquel Alsina Tarrés - Universidad de Girona
0000-0002-9619-9063

0000-0001-6625-1097

Recepción: 19.03.2021 | Aceptado: 07.04.2021

Correspondencia a través de ORCID: Miquel Alsina Tarrés

Citar: Quílez, A y Alsina, M (2021). Desarrollo profesional y formación docente online. El caso de "MiniDeportistas", un proyecto de música y movimiento. REIDOCREA, 10(18), 1-22.

Resumen: La formación continua juega un papel primordial en el desarrollo profesional del profesorado. Las enormes posibilidades del avance tecnológico, junto al contexto actual de restricciones por la Covid19, convierten la posibilidad de seguir cursos online en una de las principales opciones formativas del docente. Por medio de una investigación evaluativa, de tipo mixto cualitativo-cuantitativo, se analiza el proceso de creación, aplicación y seguimiento de un curso online de música y movimiento ("MiniDeportistas") destinado a educadores. A través de un cuestionario suministrado a los usuarios registrados ( $\mathrm{N}: 132)$, se indaga sobre diferentes áreas relativas a su perfil, motivación, uso de los materiales didácticos, y valoración de la plataforma digital. Tras el análisis de las respuestas (N:69), se pone de manifiesto el componente internacional de sus usuarios y la configuración de una comunidad de aprendizaje de amplia representación multisectorial. Entre los materiales didácticos digitalizados, los video tutoriales y las músicas creadas por los autores son los más apreciados por los participantes. A su vez, se subraya la repercusión de la formación recibida sobre la práctica en el aula de los docentes, siendo la temática interdisciplinar del curso y su formato online los elementos percibidos como portadores de mayor innovación.

Palabra clave: Educación a distancia

Professional development and online teacher training. The case of "Mini-Deportistas", a music and movement project

Abstract: Continuous training plays a key role in the professional development of teachers. The enormous possibilities of technological advance, together with the current context of restrictions due to Covid-19, make the possibility of following online courses one of the main training options for teachers. Through an evaluative research, of a mixed qualitative-quantitative type, the process of creating, applying and monitoring an online music and movement course ("Mini-Athletes") for educators is analysed. Using a questionnaire supplied to registered users ( $\mathrm{N}: 132)$, different areas related to their profile, motivation, use of teaching materials, and assessment of the digital platform are investigated. After the analysis of the responses (N: 69), the international component of its users and the configuration of a learning community with broad multisectoral representation is revealed. Among the digitized teaching materials, the video-tutorials and the music created by the authors are the most appreciated by the participants. At the same time, the impact of the training received on classroom practice of teachers is underlined, with the interdisciplinary theme of the course and its online format being the elements perceived as carriers of greater innovation.

Keyword: Distance education

\section{Introducción}

El desarrollo profesional docente, en el caso particular del colectivo dedicado a las enseñanzas musicales, se desarrolla a través de una gran diversidad de actividades, bien de tipo regular y prolongado, bien de tipo esporádico y nada sistematizado (West y Bautista, 2020). Junto a los formatos tradicionales, de carácter congresual o en las escuelas de verano, han emergido variantes ligadas a conceptos más novedosos y creativos como la constitución de comunidades de aprendizaje, la planificación de la investigación en la acción, o los proyectos colaborativos, todos ellos potencialmente efectivos para aumentar las capacidades y los resultados docentes de sus participantes, a tenor de las percepciones recabadas en el propio colectivo (Bautista y Wong, 2019; Sindberg, 2016). 
Por su parte, en las últimas décadas, la educación online se ha expandido y consolidado ampliamente en todos los niveles educativos y en situaciones formales y no formales de aprendizaje (Gros, 2018). El término e-learning tiene su origen a finales de los años ochenta, y se consolida durante los noventa (Moore, Dickson-Deane y Galyen, 2011). Según Koper (2008), el e-learning puede definirse como el uso de las tecnologías de la información y la comunicación para facilitar y mejorar el aprendizaje y la enseñanza. Para Sangrà, Vlachopoulos y Cabrera (2012) (citado en Pástor, Jiménez, Arcos, Romero y Urquizo, 2018), el e-learning puede describirse como un entorno de enseñanza y aprendizaje que utiliza las Tecnologías de la Información y Comunicación (TICs) como una herramienta para mejorar la comunicación y la interacción con los estudiantes, facilitando así la comprensión y el desarrollo del aprendizaje. A su vez, Area y Adell señalan cómo el e-learning "tiene lugar totalmente o en parte a través de una especie de aula o entorno virtual en el cual tiene lugar la interacción profesor-alumnos, así como las actividades de los estudiantes con los materiales de aprendizaje" (Area y Adell, 2009, p. 2).

Existen herramientas y aplicaciones e-learning que se utilizan para gestionar el contenido académico y ayudan al docente en el proceso de enseñanza-aprendizaje. Uno de los elementos más utilizados en entornos e-learning es el curso online, el cual permite una comunicación e interacción entre el docente y el estudiante a través de internet, de manera asíncrona y/o síncrona (Pástor et al., 2018). Para poder organizar y llevar a cabo el proceso educativo mediante el uso de un curso online, se suele utilizar un sistema de gestión del aprendizaje (LMS), denominados, coloquialmente plataformas digitales o virtuales.

Estas plataformas digitales nacieron en los años noventa, y su función era actuar como elementos facilitadores del proceso de enseñanza-aprendizaje en el ámbito educativo, preferentemente en el universitario (De Pablos, Colás, López y García, 2019). Las plataformas de e-learning permiten la interacción del usuario con el material mediante el uso de diversas herramientas informáticas (Valente, 2014). Sobre esta temática, la investigación llevada a cabo por De Pablos et al. (2019) sobre los usos de las plataformas digitales en la enseñanza universitaria constata que su presencia es plena en las instituciones universitarias del Estado español. Los cursos online se pueden seguir de forma presencial en las instituciones educativas, o como apoyo a la presencialidad. $Y$ también, como una forma de brindar un espacio de formación totalmente en línea para la superación personal o desarrollo profesional (Dousay y Trujillo, 2018).

La revisión bibliográfica nos ofrece estudios e investigaciones referentes al diseño de cursos online enfocados al ámbito universitario en los que se pretende, entre otras cosas, analizar el perfil de sus usuarios y las innovaciones formativas y didácticas desarrolladas en el nuevo medio (Jaramillo, Conde y Londoño, 2020; Pástor et al., 2018). De los MOOCs (Massive Open Online Courses), por ejemplo, se dice que son cursos gratuitos, basados en internet $o$ audiovisuales, sin restricciones para los usuarios, con delimitación temporal de inicio y fin, y que incluyen procesos de evaluación (Gea, 2015). Los cursos online, en general, parecen ser una buena alternativa para la formación continua presencial e institucional de los maestros (Gómez, Monge y García, 2016). Otros estudios, como los desarrollados por Sharif (2014), se centran exclusivamente en la evaluación de la calidad de los cursos online. Por supuesto que, en nuestros días, el uso de las -así llamadas- "plataformas de sistemas de gestión del aprendizaje", no sólo abarca la educación superior o universitaria. Si nos adentramos en el mundo del marketing digital, encontramos diferentes sectores en los que se utilizan también estas plataformas. 
Nuestro ámbito de estudio se centra, de entrada, en el sector de la creación e implantación de cursos online, centrado en el ámbito de instituciones y personas que trabajan en la documentación de productos digitales como ocurre en nuestro caso. Los productos digitales, también conocidos como infoproductos, son materiales producidos en formato digital y distribuidos en línea. Según Valente (2014), un infoproducto es un producto digital con fines educativos y formativos. Actualmente, muchos profesores que han optado por el formato online han aprovechado el medio digital para compartir sus conocimientos. Valente (2014) destaca algunas de las características de los productos digitales y nos dice que:

Estar en Internet permite llegar a todos los rincones y nichos que uno se pueda imaginar. Sin costos de impresión, tiempo de entrega o grandes inversiones en publicidad e infraestructura. Su forma de distribución es 100\% digital y su coste de producción, relativamente bajo, en comparación con otros. Su éxito suele depender en gran medida del grado de autoridad y conocimiento del autor en el área y, claro, del trabajo en publicidad para darlo a conocer y destacar sus beneficios (Valente, 2014, p. 112).

Un curso online está formado por diferentes materiales didácticos digitales. Según Real (2019), los materiales educativos constituyen el eje central de la estrategia pedagógica debido a las numerosas posibilidades didácticas que ofrecen para trabajar contenidos conceptuales, procedimentales y actitudinales, además de contribuir a la adquisición de competencias. Así, según Sabulsky, "la enseñanza no es posible de ser pensada sin materiales educativos. Desde una dimensión pedagógica, los materiales permiten el acceso a la información para transformarla en conocimiento y desde una dimensión tecnológica determinan las interacciones de acuerdo con una funcionalidad técnica preestablecida" (Sabulsky, 2009, p. 344). Diremos, en consecuencia, que la gran variedad de materiales digitales que pueden usarse con fines educativos dificulta acordar definiciones precisas e inclusivas que, a su vez, los diferencie de otro tipo de contenidos. Efectivamente, hoy en día puede argumentarse que cualquier contenido digital de calidad tiene su encaje en uno u otro contexto educativo, según la intención y propósito del educando (Aguilar, De la Vega, Lugo y Zarcol, 2014).

Actualmente, se conciben las TIC como un ecosistema digital, un espacio en continuo crecimiento, puesto que engloban tal amalgama de productos educativos (digitales) que complica su identificación y definición. Area $(2017$, p. 19) propone una clasificación o, lo que él denomina, "un intento de elaborar un inventario", e incluye en este los siguientes elementos: objeto digital, objeto digital de aprendizaje, entorno didáctico digital, libro de texto digital, Apps, herramientas y plataformas online, entornos inteligentes de aprendizaje adaptativo, materiales didácticos tangibles, y materiales digitales para la docencia. Podríamos decir, como síntesis, y en línea con el mismo autor, que el material didáctico es un objeto físico o digital, creado para generar aprendizaje en una determinada situación educativa, ya sea online o de manera presencial.

En referencia al análisis de los materiales didácticos digitales encontramos abundantes investigaciones, algunas de ellas centradas en su evaluación, como es el caso de Aguilar et al. (2014) y de Cepeda, Gallardo y Rodríguez (2017), y otras en el análisis de plataformas de contenidos educativos digitales, ubicados tanto en plataformas educativas, como comerciales e institucionales. Vale la pena destacar los trabajos de Santana, Eirín y Marín (2017) y de Castro-Rodríguez, De Castro y Hernández, (2017), que se enmarcan en el proyecto de investigación "La escuela de la sociedad digital: análisis y propuestas para la producción y uso de los contenidos digitales educativos", cuyos resultados apuntan que, pese a existir un amplio abanico de oferta en internet de materiales didácticos, con una gran variedad de contenidos y formatos, la mayoría reproducen la idea del libro tradicional, aunque enriquecido con recursos online. 
En el ámbito de los materiales didáctico-musicales, existen, a día de hoy, gran cantidad de recursos digitales disponibles en internet. Citamos algunos ejemplos que consideramos emblemáticos, empezando por la web "Educacontic" (http://www.educacontic.es) y su blog complementario, donde se exponen y comparten recursos y proyectos relativos a la educación musical; o el blog para niños "Aprendo Música" (https://aprendomusica.com) con juegos didácticos para aprender y practicar el lenguaje musical. Podemos continuar por las audiciones sobre instrumentos musicales, por ejemplo, con "Explore the World of Musical Instruments", una página web desarrollada por el proyecto MIMO (Musical Instrument Museums Online), donde se reúne información en siete idiomas sobre instrumentos musicales y sus sonidos, con ejemplos de todo el mundo. También encontramos la aplicación en línea "Incredibox" (www.incredibox.com) para crear melodías y ritmos utilizando los efectos y las voces de varios personajes protagonistas. Y en referencia a la base de datos de partituras, destacamos la "International Music Score Library Project" (https://imslp.org), biblioteca virtual colaborativa que alberga partituras musicales de dominio público y trabajos de compositores que desean compartir su música, organizada por autores, nacionalidades, instrumentación, tipo de obra o idioma. Por citar un último ejemplo, de reciente aparición, se ha creado una plataforma virtual de difusión y gestión de actividades formativas para docentes en el ámbito de la educación musical (www.music.cat) donde se pueden realizar cursos o talleres a través de clases grabadas o en streaming.

A nuestro entender, faltan estudios que aborden el análisis de los materiales didácticomusicales y digitales, sus cualidades, funciones y efectos prácticos, entre otras cuestiones. Citamos el trabajo de Vicente, Marín y Cepeda (2018), sobre una investigación que parte de un análisis de contenido de una muestra de materiales didácticos musicales para $5^{\circ}$ y $6^{\underline{a}}$ de Educación Primaria. Este estudio permite conocer las características tecnológicas, las tareas específicas y el tipo de aprendizaje musical que ofrecen las editoriales y la administración pública a través de la tecnología educativa. Los materiales analizados suponen un cambio de formato del papel al soporte digital. Sin embargo, el modelo educativo responde a un modelo tradicional y expositivo de enseñanza. Por tanto, una conclusión, y a su vez una advertencia, es que el cambio de soporte no implica necesariamente innovación educativa, porque puede pasar que el modelo de enseñanza alentado no conlleve cambio metodológico.

El proyecto "Mini-Deportistas" se originó inicialmente como unidad didáctica programada para clase de música y movimiento con alumnos de entre 5 y 6 años. Dicho proyecto fue una propuesta de solución ante una situación a la que cualquier docente se puede enfrentar, esto es, un grupo-clase con serios problemas de falta de atención, baja motivación y, a su vez, con una energía desbordante. Una situación difícil que se convirtió en un reto para ser superado. Para ello, se diseñó y creó una programación de música y movimiento conectando sus actividades a través de la temática de los deportes, basada metodológicamente en las ideas de dos grandes pedagogos musicales del siglo XX: Jacques Dalcroze y Carl Orff.

Tras los buenos resultados de este proyecto con el citado grupo-clase, "MiniDeportistas" se llevó a cabo, adaptado y ampliado, de manera presencial, con diferentes niveles de Educación Infantil y Primaria. A su vez, este mismo proyecto se puso en práctica en diversos cursos de formación del profesorado impartidos por su autora en España y en Brasil. A partir de la buena acogida de estos cursos, se consideró oportuna la idea de convertir "Mini-Deportistas" en un curso online para docentes, con el objetivo de generar un material digitalizado que les aportase nuevas estrategias, actividades y recursos para planificar y gestionar sus clases. 
En la siguiente infografía se muestra el planteamiento del proyecto "Mini-Deportistas" y su aplicación en diferentes escenarios.

\section{Planteamiento de "Mini-Deportistas"}

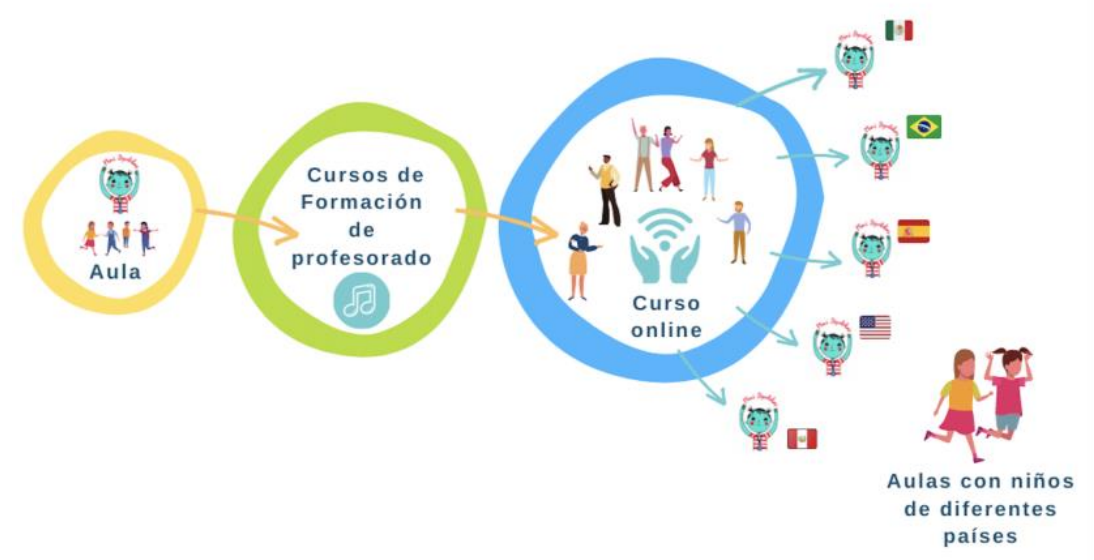

Figura 1. Infografía con el planteamiento del proyecto "Mini-Deportistas"

\section{Objetivos}

Se ha realizado un estudio, entre mitad y final del primer curso de impartición de "MiniDeportistas" en su formato online, con la intención de recabar los datos necesarios para responder a los siguientes objetivos de investigación:

1. Describir el perfil personal y profesional de los usuarios del curso "MiniDeportistas" e indagar en sus motivaciones formativas.

2. Recabar sobre el uso y valoración que se da a los contenidos digitales facilitados a través de la plataforma online.

3. Recoger qué resultados y transformaciones de la práctica en el aula se producen al aplicar la propuesta.

\section{Método}

\section{Participantes, instrumento y procedimiento}

La muestra del estudio la constituyen, de entrada, los 132 usuarios del curso "MiniDeportistas" que accedieron a la formación y a los materiales de la plataforma a lo largo del curso 2019-2020. A todos ellos se les envió un cuestionario online del cual se obtuvieron un total de 69 respuestas.

La investigación realizada se enmarca en el paradigma sociocrítico, desde el enfoque de la investigación evaluativa (valoración, uso y repercusiones de un producto o proyecto sobre sus usuarios), con una metodología mixta, cualitativa y cuantitativa, tras la aplicación de un cuestionario (Leavy, 2017). En dicho cuestionario, con formato anónimo, se incluyeron diferentes tipologías de preguntas siguiendo el enfoque mixto, incluyendo la opción múltiple, las preguntas abiertas y las preguntas cerradas. Un primer prototipo de cuestionario fue sometido a un pilotaje por tres expertos externos, cuyas aportaciones se incorporaron a la herramienta final. Una vez validado, el cuestionario 
se tradujo al portugués y se digitalizó a través de los formularios de Google Forms en versión bilingüe.

El cuestionario se organizó con base a cinco secciones: en primer lugar, se contempló un apartado con la información general sobre los datos personales de los participantes en el estudio. Una segunda sección sobre la plataforma online, recogiendo la valoración de los usuarios sobre el acceso y el uso de la plataforma; la tercera sección referida a los autores y su metodología docente; la cuarta sección destinada a los contenidos del curso y, por último, la quinta sección referente la valoración de la incidencia que este curso ha tenido en la labor docente de los participantes.

El trabajo de este proyecto fue desarrollado en cuatro etapas. Cuatro años de trabajo, desde su idea original hasta la creación final del curso online. A continuación se detallan, sintéticamente, cada una de las etapas del procedimiento seguido:

\section{Primera etapa: idea original, diseño y creación de la unidad didáctica}

El proyecto "Mini-Deportistas" se creó con la intención de mejorar las actitudes de un grupo de alumnos a partir del trabajo de música y movimiento. Para ello, se diseñó una unidad didáctica de música y movimiento conectando sus actividades a través de la temática de los deportes y basada en las pedagogías musicales de Carl Orff (Munic,1985-1992) y Jacques Dalcroze (Viena, 1865- Ginebra,1950). A través del juego simbólico, los alumnos se convierten en "Mini-Deportistas", desarrollando con este nuevo rol, las actividades musicales propuestas.
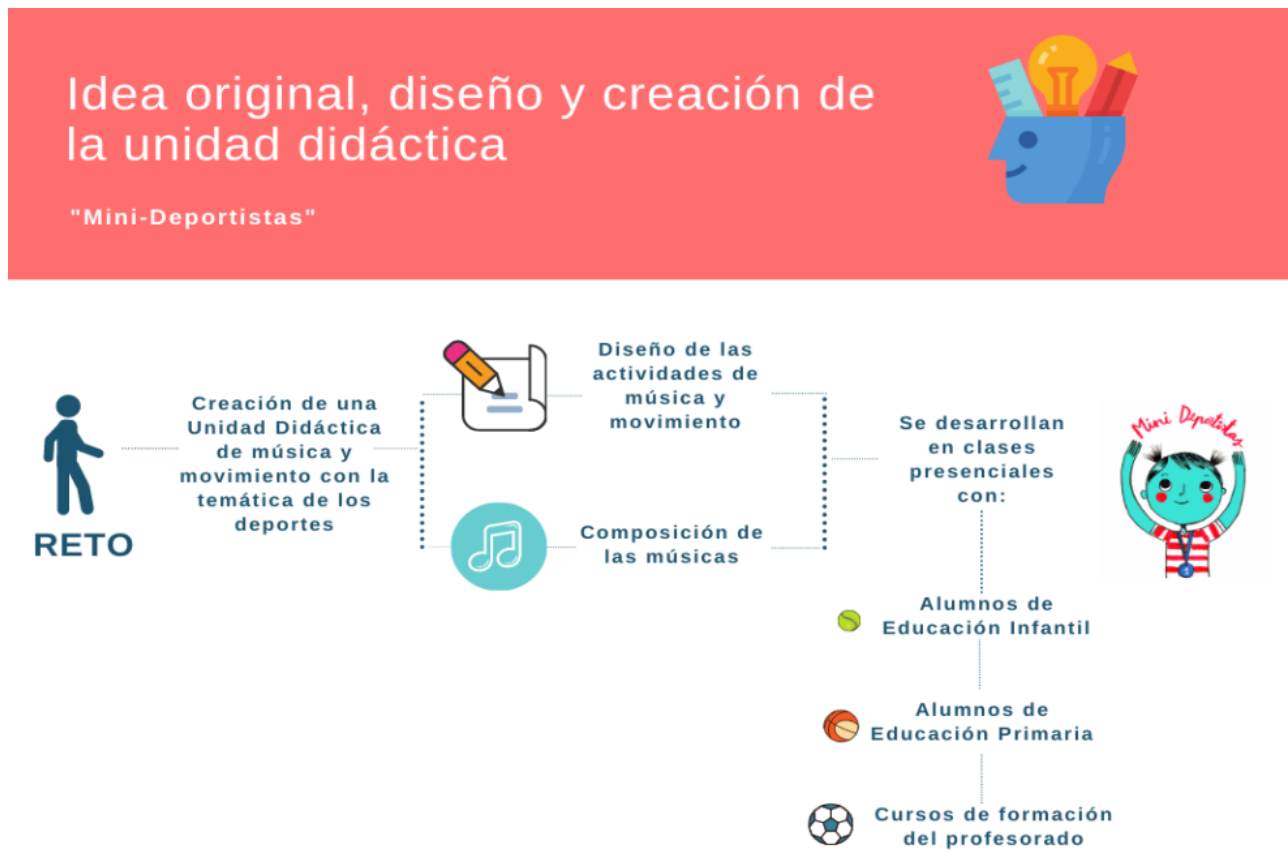

Figura 2. Infografía sobre la primera etapa del proyecto

Durante tres cursos lectivos, se diseñaron las actividades de música y movimiento para los diferentes niveles de Educación Infantil y Primaria y se compusieron las músicas adecuadas a los objetivos y contenidos musicales de dichas actividades, de modo que cada una de las músicas tiene varias propuestas didácticas. En este periodo, se probaron las músicas y todas las actividades propuestas con los alumnos de educación 
infantil, primaria y en cursos de formación del profesorado y se efectuaron los cambios necesarios.

\section{Segunda etapa: definición y digitalización de los materiales didácticos del curso online}

En esta etapa del proyecto, se definieron y se digitalizaron los materiales didácticos que iban a componer el curso.

\section{Pilares del proyecto}

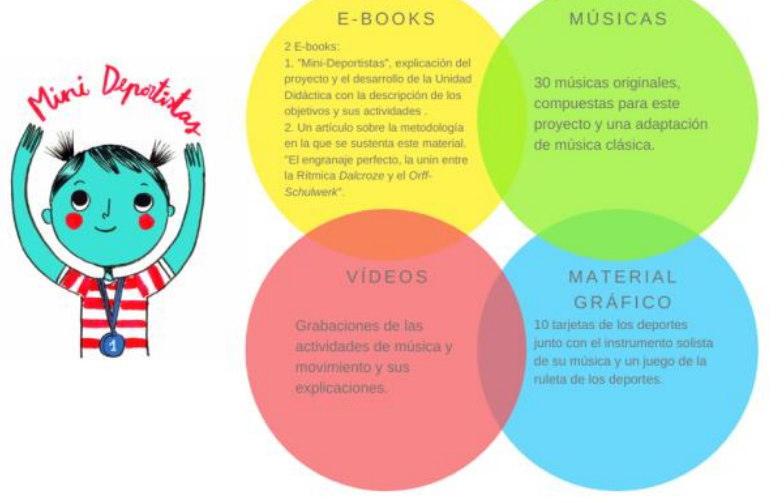

Figura 3. Infografía sobre los materiales del proyecto

E-book: se redactó un e-book del proyecto "Mini-Deportistas", el cual consta de una Introducción, donde se explica el proyecto y se orienta a su correcta utilización, y de la Unidad Didáctica, articulada por sus músicas en tres módulos, correspondientes a las partes de una sesión de Música y Movimiento. Cada música se relaciona con diferentes propuestas didácticas, detallando sus objetivos y siempre descritas de menor a mayor dificultad. Así, las músicas y la propuesta de actividades del Módulo 1 giran en torno al calentamiento corporal y vocal de los Deportistas. Las músicas y actividades del Módulo 2 conforman la parte central, los deportes y, por último, las del Módulo 3 son actividades grupales y apropiadas para finalizar la sesión.

Definición y digitalización de los materiales didácticos del curso online

1
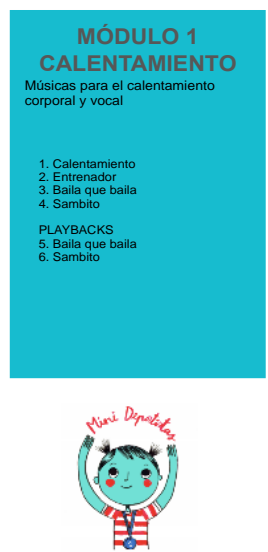

2

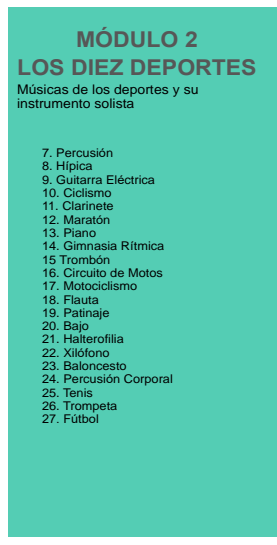

3

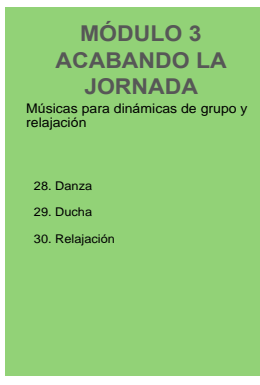

EL E.BOOK TIENE UN TOTAL DE 10

Figura 4. Infografía sobre los módulos del proyecto 
Con esta distribución de las músicas y sus actividades por módulos se ofrecen estrategias a los docentes para planificar las sesiones de música y movimiento. Por tanto, en la preparación de la sesión, lo ideal es que el educador escoja algunas actividades del Módulo 1, siempre de menor a mayor dificultad. Una o varias músicas para trabajar actividades del Módulo 2 y, finalmente, algunas actividades del Módulo 3.

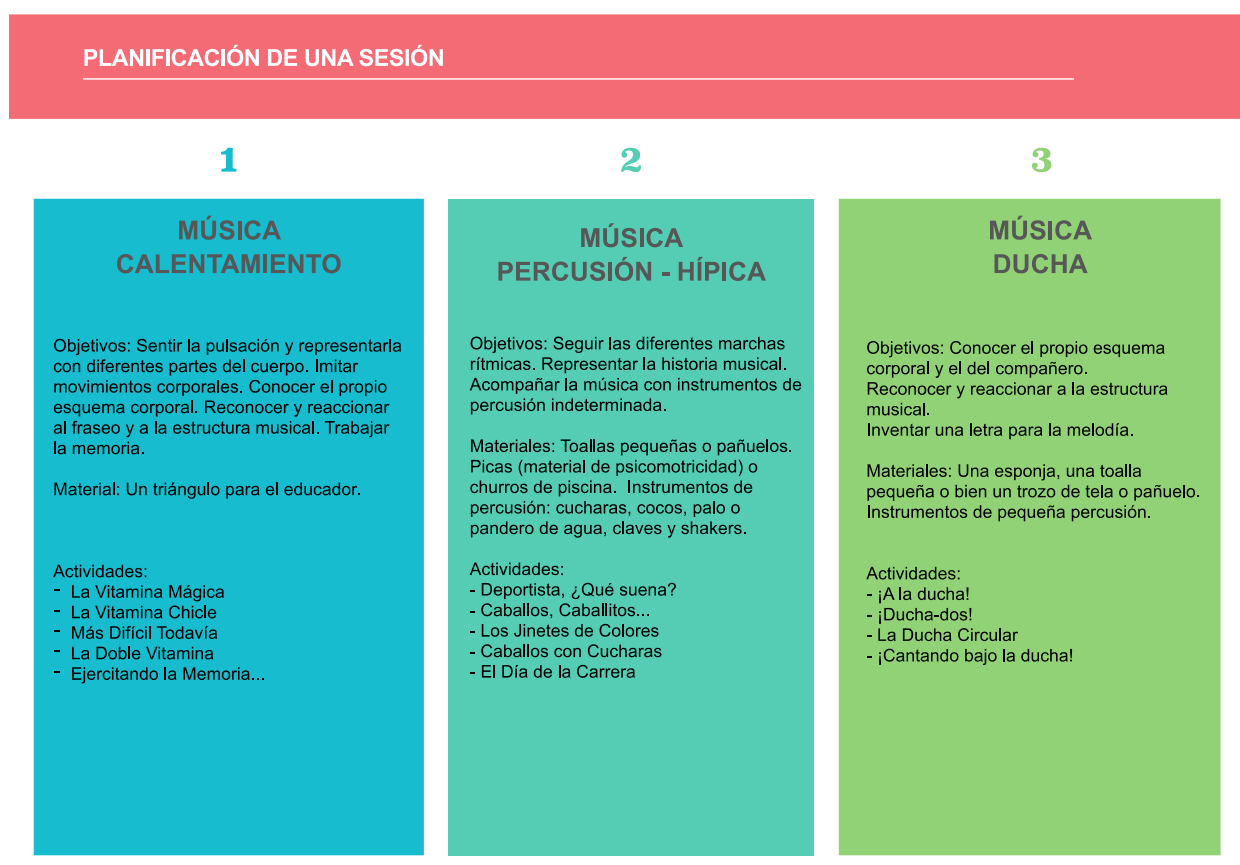

Figura 5. Infografía con un ejemplo de planificación de una sesión

Vídeos: se realizaron las grabaciones de las actividades de música y movimiento junto con las explicaciones de las mismas, en total 109 vídeos. Para dichas grabaciones se contó con la colaboración esporádica de 12 profesores (previamente formados) de música y movimiento de diferentes centros educativos, y con un grupo de 5 niños que contribuyeron a la ilustración de los ejercicios.

Músicas: siete músicos profesionales realizaron la grabación de las diferentes músicas compuestas para este proyecto por los propios autores-formadores del curso, hasta un total de 29 músicas originales y una versión de un tema clásico. La grabación se llevó a cabo en un estudio de grabación profesional.

Proyecto gráfico: una ilustradora profesional se encargó de dar una imagen uniforme y coherente al proyecto. Elaboró una ruleta de los deportes y 10 tarjetas correspondientes a cada uno de los deportes presentados en el proyecto junto con el instrumento solista de su música correspondiente.

\section{Tercera etapa: elección de la plataforma y lanzamiento del curso online}

Se exploró sobre las plataformas que existían en el mercado, con la finalidad de escoger la más adecuada. Finalmente, se eligió la plataforma Hotmart que daba respuesta a todas las necesidades planteadas. En septiembre del 2019 se realizó el lanzamiento del curso "Mini-Deportistas" (https://www.hotmart.com/product/mini-deportistas), y se difundió a través de las redes sociales y vía mailing, en especial a los profesores y educadores que asistieron a los cursos de formación de sus autores. 
En la plataforma se encuentran disponibles todos los materiales descritos anteriormente y, a excepción de los vídeos, el resto de los materiales se pueden descargar, previo registro y suscripción con dos años de vigencia.

\section{Cuarta etapa: uso y repercusión del curso online "Mini-Deportistas" en el aula de sus usuarios}

Esta última etapa, se refiere a la puesta en práctica y el uso que los usuarios 0 participantes del curso realizan de los materiales de "Mini-Deportistas".

Desde el lanzamiento del curso, se han recabado un número considerable de comentarios y vídeos que los usuarios del curso han enviado de forma espontanea a medida que avanzaban en el programa, hecho que se ha producido a través de la plataforma del curso, las redes sociales, y el correo electrónico. Ante este hecho y con la finalidad de conocer el grado de satisfacción y la incidencia que ha tenido el curso "Mini-Deportistas" en los usuarios y en los alumnos de estos, se aplicó un cuestionario online.

\section{Resultados}

Sobre el total de respuestas recogidas $(\mathrm{N}=69)$, un alto porcentaje de los participantes del curso se ubica en España y en Brasil, aunque también hay usuarios residentes en EE. UU., Perú y México. Entre ellos, el 78,5\% son mujeres y el 21,5\% son hombres, porcentaje que refuerza la prevalencia del género femenino en la docencia musical. En cuanto a la edad, esta se enmarca entre los 22 y los 72 años, siendo el rango de edad de los 30 a 40 años el que tiene mayor representatividad. En referencia a su profesión, los usuarios son, mayoritariamente, maestros de música de infantil y primaria, y profesores de escuela de música (ver Figuras 6 y 7 ).

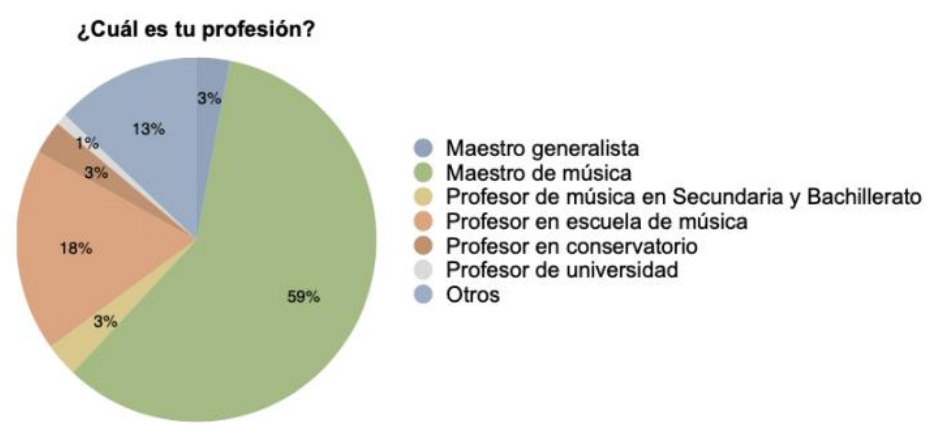

Figuras 6. Datos laborales de la muestra

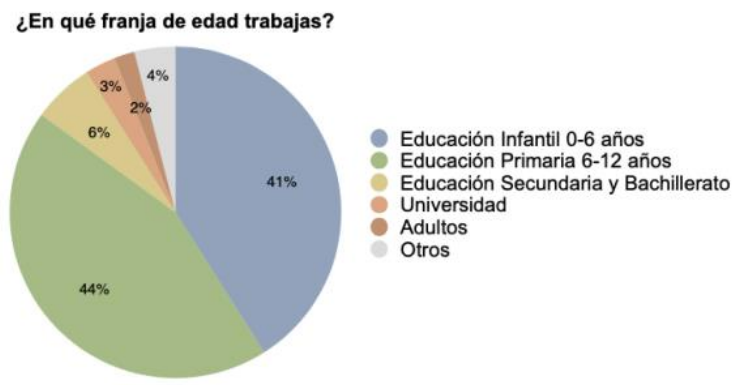

Figura 7. Dedicación profesional de la muestra 
El 57\% de los usuarios había realizado algún otro curso online con anterioridad y la temática había sido mayoritariamente en el área de educación y educación musical. Entre los motivos que los alumnos aluden sobre por qué eligieron el curso, casi la mitad expresan que el principal motivo fue que conocían a los autores que lo impartían; el segundo motivo es la búsqueda de nuevos materiales y, en tercer lugar, es la temática el factor decisivo. Analizando estos resultados, destacamos la importancia que tiene en los usuarios conocer a los autores y haber realizado algún curso de formación de manera presencial con ellos para posteriormente acceder al curso online (ver Figura 8).

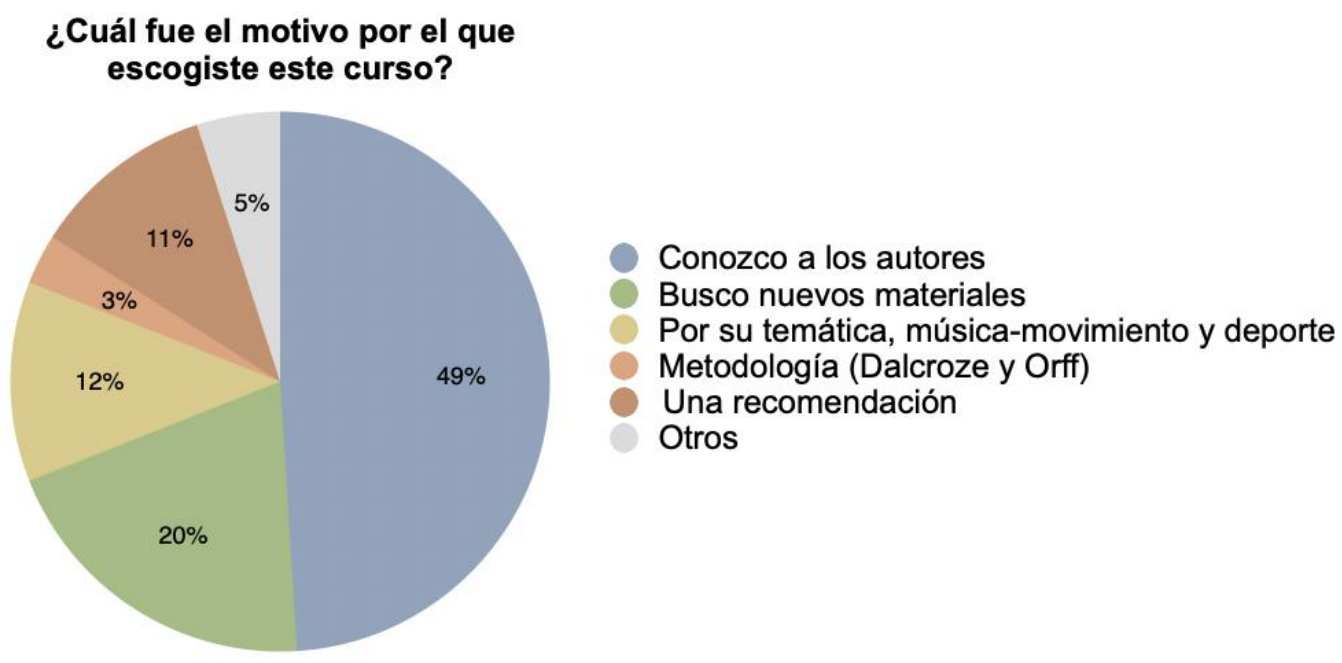

Figura 8. Abanico motivacional de la muestra

Referente al segundo apartado del cuestionario, un alto porcentaje de los usuarios consideró que la plataforma está bien diseñada y organizada por módulos y que resulta sencilla e intuitiva. Con lo cual, es una plataforma de fácil manejo para los usuarios. Para el buen desarrollo de este tipo de cursos es imprescindible realizar un estudio sobre la gran variedad de plataformas que existen en el mercado y seleccionar la plataforma que más convenga y que mejor se adecúe al autor y al tema propuesto; ya que no existe una plataforma perfecta, sino una que se adapta mejor a las necesidades del curso.

La mayoría de los usuarios está también totalmente de acuerdo en que la plataforma es una herramienta eficaz para enseñar y aprender contenidos sobre "Música y Movimiento" (ver Figura 9). Dentro de las respuestas a una serie de preguntas abiertas, destacan comentarios que reflejan la importancia de la plataforma para los usuarios:

- Comentario 1: "Me parece innovadora la plataforma en sí. Tener los vídeos con las actividades explicadas y ejemplificadas".

- Comentario 2: "Me gusta mucho su formato, la plataforma online, para poder ver las actividades en cualquier momento, desde cualquier lugar".

Esta valoración positiva por parte de los usuarios, refuerza la idea inicial del proyecto, consistente en digitalizar los materiales y ofrecerlos disponibilizados en una plataforma online, donde resulte efectivo aprender a partir de los videos y poder descargar las músicas, los documentos gráficos y los e-books con toda la información de las actividades. 
Otros usuarios, a su vez, realizaron una comparativa entre la plataforma del curso online y el libro, tal y como lo muestran los siguientes comentarios:

- Comentario 3: "Es el único curso online que conozco de música y movimiento. Existen muchos libros pero la verdad que hoy en día, con toda la tecnología que existe, merece la pena este formato".

- Comentario 4: "Valoro que sea un curso online, que no sea un libro. Una imagen vale más que mil palabras".

En cuanto al tercer apartado, sobre los autores y los materiales, todos los participantes opinan que los autores dominan la materia y que tanto los materiales que presentan como su didáctica son adecuados. Del mismo modo, la metodología, basada en las pedagogías activas (métodos Orff y Dalcroze), se considera efectiva (ver Figura 10).

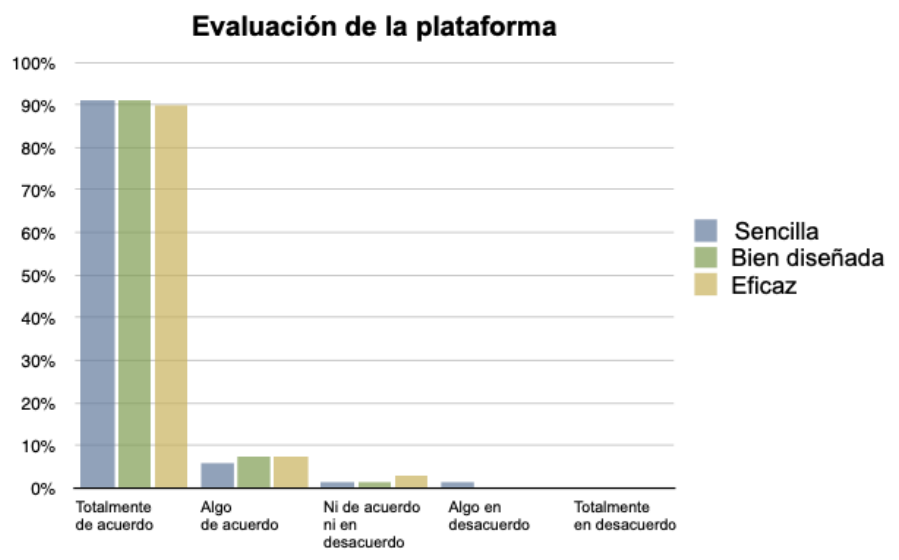

Figuras 9. Respuestas en relación con la valoración de la plataforma

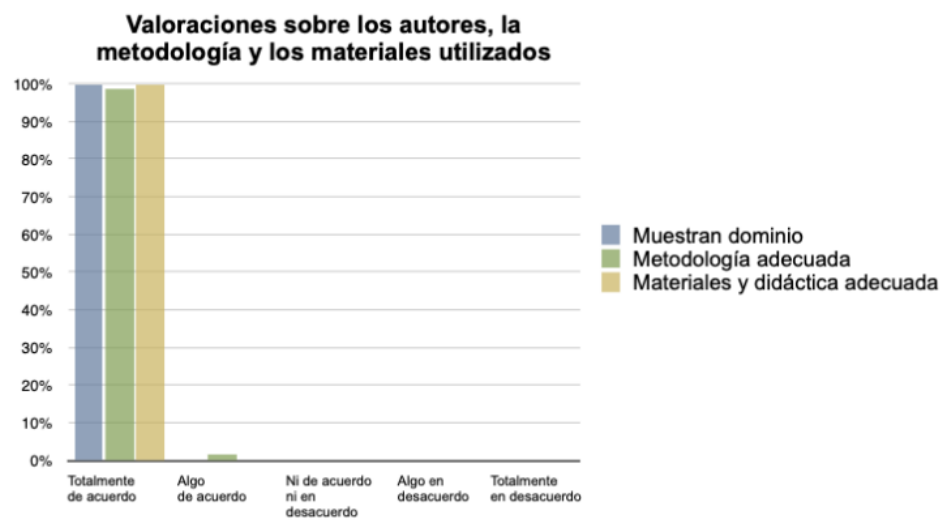

Figuras 10. Respuestas en relación con la impartición del curso

Algunos comentarios de los usuarios destacan su interés por la fundamentación metodológica del proyecto "Mini-Deportistas":

- Comentario 5: "Me interesan recursos sobre educación musical y movimiento bajo el enfoque Dalcroze y Orff".

- Comentario 6: "Es una metodología muy activa con músicas diferentes y motivadoras". 
Otros comentarios se refieren a los autores y a sus materiales, vinculando una cosa con la otra:

- Comentario 7: "Conozco a los autores y confío plenamente en sus materiales"

- Comentario 8: "Los materiales de estos autores son de calidad. Ya hice otro curso online suyo".

Los vídeos y las músicas del proyecto son los materiales mejor valorados por los usuarios, destacando la importancia del soporte audiovisual y los archivos de audio como recursos esenciales en un curso online sobre música y movimiento (ver Figura 11). La totalidad de las respuestas muestran estar "totalmente de acuerdo" en que los vídeos de las actividades resultan atractivos y adecuados y que las músicas compuestas para este proyecto ayudan a realizar las diferentes actividades propuestas. Además, la mayoría de los usuarios está "totalmente de acuerdo" en que los e-books y el material gráfico sirven como soporte para entender el planteamiento del curso (ver Figura 12).

Analizando estos resultados, se valora muy positivamente el diseño de las actividades y la composición de sus músicas. Destacamos algunos comentarios en los que se hace referencia a estos aspectos:

- Comentario 9: "Las canciones son muy creativas".

- Comentario 10: "Este curso online ofrece música original y objetivos que van justo a mis necesidades educativas".

- Comentario 11: "Me gusta que sea un curso en línea donde pueda ver videos de las actividades tantas veces como quiera".

En relación al último apartado, el referido a la experiencia de los usuarios, es posible afirmar, a partir de las respuestas recibidas, que una gran mayoría manifestó haber podido llevar a cabo algunas actividades del curso "Mini-Deportistas", más de la mitad lo hizo en clases presenciales, mientras otra parte lo hizo en clases online. También, minoritariamente, algunos lo practicaron en casa con la familia.

La gran mayoría de los usuarios manifestaron estar "totalmente de acuerdo" en que las enseñanzas recibidas son (o serán) útiles para su ámbito profesional; que le ayuda (o ayudará) en la planificación de sus clases y que este material les ayuda (o ayudará) a hacer la clase más activa, más dinámica. Este era uno de los objetivos en la elaboración del curso, aportar estrategias a los docentes para su día a día en el aula. Destacamos estas aportaciones de los participantes:

- Comentario 12: "Este curso online ha sido mi salvación durante las clases del confinamiento. Todas mis clases online, de los diferentes niveles de educación infantil han trabajado con los Mini-Deportistas. ¡Muchas gracias y felicidades por todo el trabajo!".

- Comentario 13: "Me ha ayudado mucho en la planificación de mis clases y en darles una continuidad. Los alumnos se mostraban muy entusiasmados. Muchas gracias por este valioso material".

También, en la mayoría de las respuestas, los usuarios están "totalmente de acuerdo" en que el curso "Mini-Deportistas" les parece un material innovador y en que se puede trabajar de manera interdisciplinar, tal y como queda de manifiesto en sus comentarios:

- Comentario 14: "Es un curso para trabajarlo totalmente de manera interdisciplinar".

- Comentario 15: "Trabajamos de forma interdisciplinaria, lengua portuguesa, educación física, música y bellas artes ¡Nos encanta este proyecto!” 


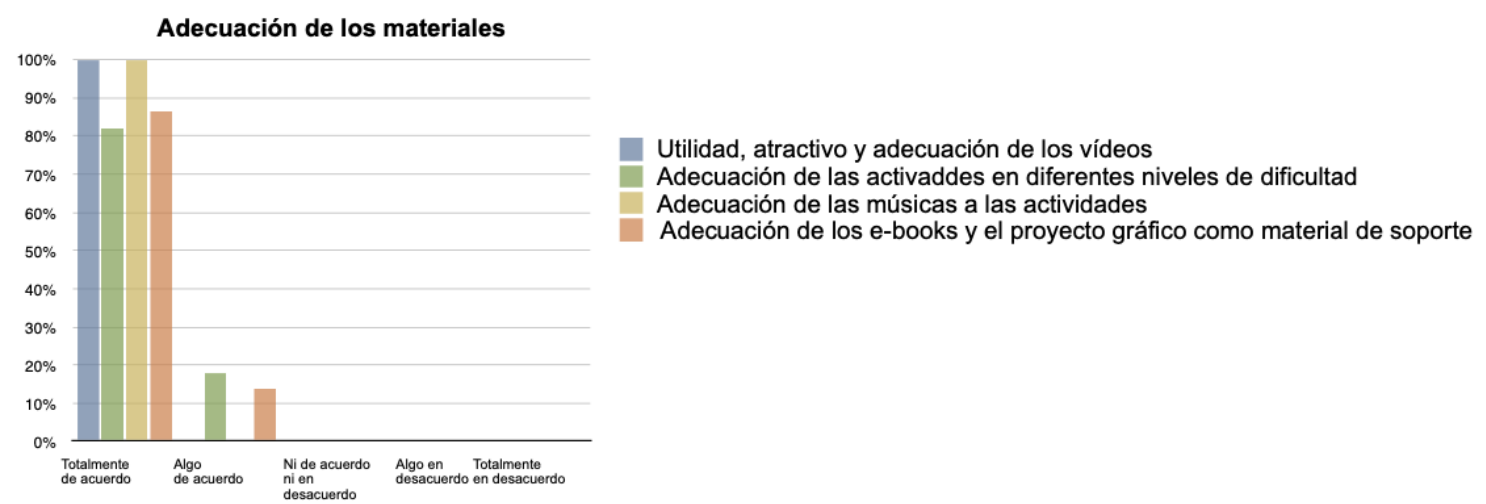

Figura 11. Respuestas en relación con la valoración de los materiales

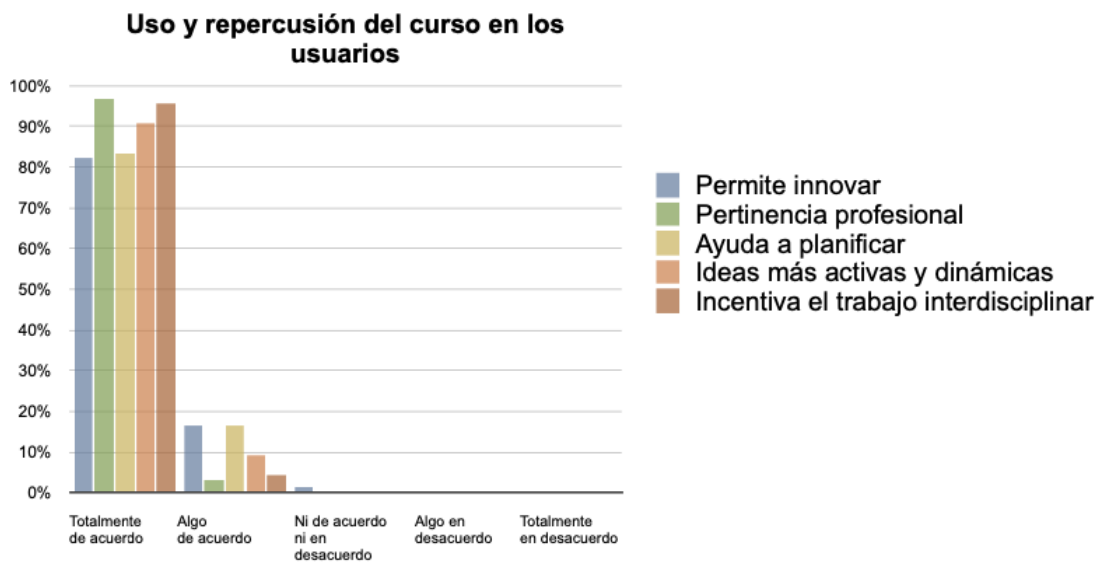

Figura 12. Respuestas en relación con los beneficios reconocidos por los usuarios

En referencia a la innovación del proyecto "Mini-Deportistas", los aspectos considerados más relevantes son, por este orden: "la temática", el hecho de trabajar la música y el movimiento a través del deporte; "que sea un curso online", ubicado en una plataforma; "sus músicas", composiciones originales y la relación de cada deporte con un instrumento musical; "sus actividades", por ser creativas; y "los materiales", que se proponen para el desarrollo de las actividades (ver Figura 13).

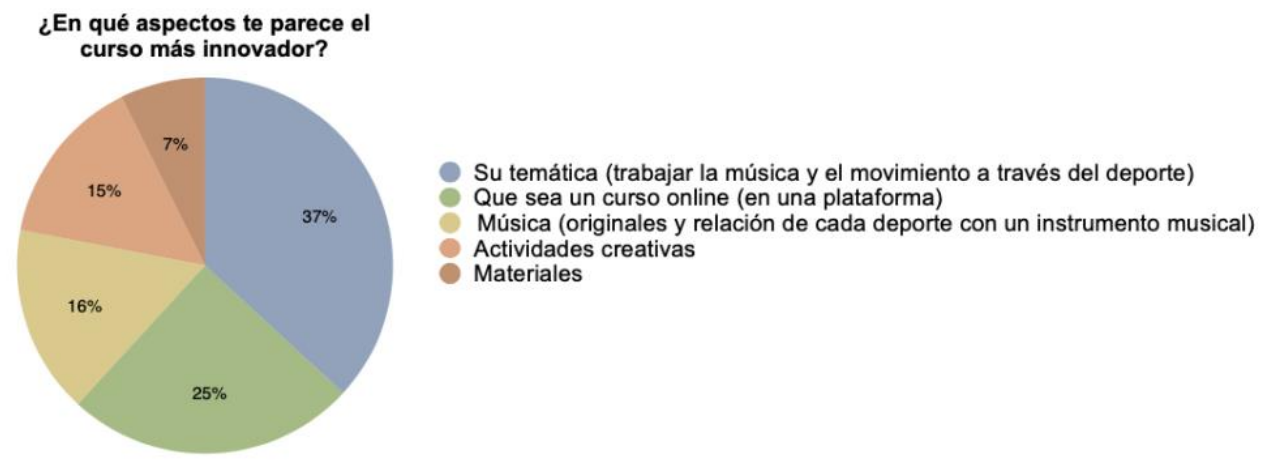

Figura 13. Valoración de los usuarios sobre la innovación 
En cuanto al manejo y tipo de contenidos, la gran mayoría de los usuarios manifiesta que está "totalmente de acuerdo" en que el proyecto "Mini-Deportistas" permite trabajar los contenidos de su programación, destacando: "ritmo y movimiento"; "psicomotricidad, percepción auditiva"; "entonación y canción"; "parámetros del sonido", como los contenidos más trabajados. Algunos usuarios valoran muy positivamente "poder trabajar todos los contenidos musicales a través de una unidad didáctica, con una única temática".

Todas las respuestas están "totalmente de acuerdo" en que el binomio de Música y Movimiento es esencial para trabajar en la clase de música con alumnos de educación infantil y primaria. Por lo que este curso les brinda herramientas y recursos para desarrollar de mejor manera sus sesiones.

En cuanto al grado de motivación de los niños y niñas de educación infantil y primaria que recibieron las enseñanzas de "mini-deportistas", la mayoría fue "Excelente" o "Muy bueno". Este es uno de los aspectos más relevantes, puesto que la idea original del proyecto era, precisamente, despertar la motivación en las clases de música y movimiento. llustran estos datos los últimos comentarios:

- Comentario 16: "Es un material muy práctico que ha gustado mucho a los niños y las niñas, ¡buen trabajo!".

- Comentario 17: "Mis alumnos adoran este proyecto".

\section{Discusión}

De acuerdo con los resultados del cuestionario, el curso "Mini-Deportistas" ha llegado a diferentes partes del mundo, configurándose una comunidad de aprendizaje internacional y multisectorial (Infantil, Primaria, escuelas de música y conservatorios). En concreto, cuenta con participantes de cinco países, de los cuales hay un mayor número de usuarios de España y Brasil y, en menor medida, México, EE. UU. y Perú. Esto visibiliza el hecho de que el curso no solamente es funcional en un entorno como el español sino que, gracias, esencialmente, al formato online, también es aplicable en otros países, con contextos culturales y educativos distintos entre ellos. Lo cual pone de manifiesto que las necesidades formativas de los docentes en educación musical, en un contexto internacional -en este caso iberoamericano-, son similares y compartidas con independencia de la nacionalidad de los participantes.

Este curso se imparte a través del medio tecnológico (una plataforma accesible desde internet) y la digitalización de todos los materiales (libros, guías, tutoriales, ejemplos, audiciones y documentos videográficos). Los resultados obtenidos ponen de relieve la importancia que tiene el desarrollo de plataformas digitales y entornos online en la formación permanente del profesorado, permitiendo optimizar el tiempo y llegar a un mayor número de alumnado (Calderón-Garrido, Cisneros, García y de las HerasFernández, 2019). A su vez, la mitad de los usuarios que respondieron el cuestionario afirmaron que conocer a los autores, tras realizar cursos presenciales con ellos, había sido un elemento determinante. Otros usuarios del curso que no conocían de entrada a los autores manifiestan interés en realizar algún curso presencial con ellos. Con ello, cabe concluir que una parte esencial del atractivo de una oferta formativa online puede hallarse en la posibilidad de realizar talleres o cursos presenciales, como contacto previo o posterior con los materiales digitalizados y sus creadores. Siendo pues, finalmente, un formato más afín al modelo híbrido el que ofrecería un mayor atractivo.

En referencia a las motivaciones de los participantes, una gran mayoría de profesores y profesoras que participaron en el curso "Mini-Deportistas" manifestaron que buscaban 
materiales e ideas nuevas para el día a día del aula. Concretamente, sobre los materiales digitales que se ofrecen en la plataforma, se concluye que son los vídeos y las músicas originales los productos mejor valorados, lo cual hace evidente que, en un curso de estas características, el contenido audiovisual y las audiciones resultan materiales eficaces y coherentes con el medio digital en el que se circunscriben. También toma protagonismo el valor de la retroacción e interacción entre docentes y usuarios, o entre los mismos participantes.

Las respuestas al cuestionario también señalan la importancia de la temática del curso, considerada como el elemento más creativo e innovador. En este sentido, el diseño de la propuesta incide en centrar toda la secuencia didáctica alrededor de un mismo tema, los deportes, convirtiendo los alumnos en protagonistas de una puesta en escena basada en las dinámicas del juego simbólico, la asunción de roles y simulación de situaciones de toda índole en consonancia con el tema. Una temática que, según las respuestas de los usuarios, es excelente para lograr la motivación de los niños, tomando en cuenta que es el profesor el encargado de diseñar propuestas didácticas que aseguren esa centralidad en el estudiante (Cela-Ranilla y Gisbert, 2013).

En referencia al tercer objetivo, consistente en valorar los resultados de la formación en el aula de los docentes, González y Cutanda (2017) apuntan que se debe valorar si el impacto de la formación docente influyó, en alguna medida, en aspectos como la planificación de su enseñanza, la utilización de nuevas metodologías, el clima del aula, la implicación del alumnado, o los resultados de aprendizaje. Constatamos como la gran mayoría de los usuarios afirman que las enseñanzas recibidas son, o serán, útiles para su ámbito profesional; que les ayudan, o ayudarán, en la planificación de sus clases, y que este material les ayuda, o ayudará, en hacer la clase más activa, más dinámica, y más motivadora para sus alumnos. Son los argumentos en los que parece incidir la formación en mayor medida, aportando estrategias a los docentes que supongan una verdadera transformación de su día a día en el aula.

Según Valente (2014), la calidad y el éxito de un curso online puede depender, en gran medida, del grado de experticia de los autores. El dominio de la materia y el conocimiento aplicado en su creación va a ser determinante para la elección y gradación de contenidos, por ejemplo. Como docentes y formadores debemos incidir en nuestros alumnos desde una visión que debe ser, como se ha dicho, de empoderamiento y transformación. Esto implica desarrollar un perfil profesional docente abierto a la innovación "que someta a crítica los conocimientos acumulados, asimilados y acomodados y sepa producir en él mismo un cambio personal al servicio de su competencia profesional" (Cela- Ranilla et al. 2017, p. 417). En este sentido, el curso "Mini Deportistas" nos permite materializar y visualizar en sus usuarios, de forma muy evidente, los presupuestos de la secuencia didáctica transformativa y encauzar aprendizajes que tiendan a ese proceso de cambio.

Creemos que el análisis de este proyecto formativo ("Mini Deportistas") puede servir de ejemplo para otros enfoques docentes similares, que cumplan con el propósito de fomentar el desarrollo profesional del profesorado, desde la base de la incentivación de la creatividad del docente. Supone, a su vez, un modelo a seguir para todo formador que pretenda editar digitalmente sus propios materiales didácticos y compartirlos en la red. En la misma dirección, se pone de relieve la importancia de la presencia continuada de la tecnología en las aulas, la cual, junto a las mejoras generalizadas de conectividad en los centros, debe permitir que "profesorado y alumnado pasen de ser consumidores de materiales didácticos a prosumidores y dinamizar el desarrollo de la competencia digital en educación" (Sanabria, Quintín y Peirats, 2017, p.65). Finalmente, para ahondar y dar más consistencia a nuestras conclusiones, el estudio debería completarse con 
otras experiencias online de formación permanente del profesorado, también en otras materias, o desde otros contextos culturales. Ello debería permitir la definición y estandarización de elementos de eficacia en entornos formativos online de desarrollo profesional docente.

\section{Referencias}

Aguilar, I, De la Vega, JA, Lugo, O y Zarco, A (2014). Análisis de criterios de evaluación para la calidad de los materiales didácticos digitales. Revista Iberoamericana de Ciencia, Tecnología y Sociedad - CTS, 9(25), 73-89.

Area, M (2017). La metamorfosis digital del material didáctico tras el paréntesis Gutenberg. Revista Latinoamericana de Tecnología Educativa (RELATEC), 16(2), 13-28.

Area, M y Adell, J (2009). eLearning: Enseñar y aprender en espacios virtuales. En J De Pablos (Coord.), Tecnología Educativa. La formación del profesorado en la era de Internet (391-424). Málaga: Aljibe.

Bautista, A y Wong, J (2019). Music teachers' perceptions of the features of most and least helpful professional development. Arts Education Policy Review, 120(2), 80-94.

Calderón-Garrido, D, Cisneros, P, García, I, Fernández, D y de las Heras-Fernández, R (2019). La tecnología digital en la educación musical: una revisión de la literatura científica. Revista Electrónica Complutense De Investigación En Educación Musical - RECIEM, 16, 43-55.

Castro-Rodríguez, MM, De Castro, A y Hernández, VM (2017). Análisis de plataformas educativas digitales comerciales españolas destinadas a Educación Primaria. Revista Latinoamerica de Tecnología Educativa (RELATEC), 16(2), 49-62.

Cela-Ranilla, JM y Gisbert, M (2013). Learning Patterns of First Year Students. Revista de Educación, 361, 171-195.

Cela-Ranilla, JM, Esteve, V, Esteve, F, González, J y Gisbert, M (2017). El docente en la sociedad digital: Una propuesta basada en la pedagogía transformativa y en la tecnología avanzada. Profesorado. Revista de currículum y formación del profesorado, 21(1), 403-422.

Cepeda, O, Gallardo, IM y Rodríguez, J (2017). La evaluación de los materiales didácticos digitales. Revista Latinoamerica de Tecnología Educativa (RELATEC), 16(2), 79-95.

De Pablos, JM, Colás, MP, López Gracia, A y García-Lázaro, I (2019). Uses of digital platforms in Higher Education from the perspectives of the educational research. REDU. Revista de Docencia Universitaria, 17(1), 59-72.

Dousay, TA y Trujillo, NP (2019). An examination of gender and situational interest in multimedia learning environments. British Journal of Educational Technology, 50(2), 876-887.

Gea, M (Coord.) (2015). MOOC y criterios de calidad. Madrid: CRUE.

González, MT y Cutanda, MT (2017). La formación continuada del profesorado de enseñanza obligatoria: Incidencia en la práctica docente y el aprendizaje de los estudiantes. Profesorado. Revista de currículum y formación del profesorado, 21(3), 103-122.

Gómez, M, Monge, C y García, A (2016). La perspectiva de los formadores acerca de los MOOC: un estudio inicial. En M Gómez, A García y C Monge (Eds), La cultura de los MOOCs (199-222 ). Madrid: Editorial Síntesis.

Gros, B (2018). La evolución del e-learning: del aula virtual a la red. RIED. Revista Iberoamericana de Educación a Distancia, 21(2), 69-82.

Jaramillo, CO, Conde, GE y Londoño, G (2020). Modelo de diseño didáctico para la construcción de cursos virtuales: Una propuesta en la modalidad de educación a distancia de la Universidad de la Amazonia. Academia Y Virtualidad, 13(1), 23-36.

Koper, R (2008). Open Source and Open Standards. En JM Spector (Ed.), Handbook of research on educational communications and technology (3rd ed, Vol. 31, 355-368). New York: Lawrence Erlbaum Associates.

Leavy, P (2017). Research design. New York: Guilford Press.

Moore, JL, Dickson-Deane, C y Galyen, K (2011). E-Learning, online learning, and distance learning environments: Are they the same? Internet and Higher Education, 14(2), 129-135.

Pástor D, Jiménez J, Arcos G, Romero M, y Urquizo L (2018). Patrones de diseño para la construcción de cursos on-line en un entorno virtual de aprendizaje. Ingeniare. Revista chilena de ingeniería, 26(1), 157-171.

Real, C (2019). Materiales Didácticos Digitales: un recurso innovador en la docencia del siglo XXI. 3C TIC. Cuadernos de desarrollo aplicados a las TIC, 8(2), 12-27.

Sanabria, AL, Ávarez, Q y Peirats, J (2017). Las políticas educativas en la producción y distribución de materiales didácticos digitales. Revista Latinoamericana de Tecnología Educativa RELATEC, 16(2), 63-77.

Santana, PJ, Eirín, R y Marín, D (2017). Análisis y evaluación de portales institucionales en España. Los casos de Canarias, Galicia y Valencia. Revista Latinoamericana de Tecnología Educativa (RELATEC), 16(2), 29-48.

Sabulsky, G (2009). Materiales educativos que recuperen el hacer y el pensar del profesor. En S Pérez y A Imperatore (ed.), Comunicación y educación en entornos virtuales de aprendizaje: perspectivas teórico-metodológicas (344-351). Buenos Aires: Universidad Nacional de Quilmes.

Sharif, A (2014). Quality of online courses. Tesis Doctoral: Universitat Rovira i Virgili.

Sindberg, LK (2016). Elements of a successful professional learning community for music teachers using comprehensive musicianship through performance. Journal of Research in Music Education, 64(2), 202-219. 
Valente, C (2014). Modalidades de edición en géneros digitales. En I Casanovas, MG Gómez y E Rico (Eds.) II Jornadas de Investigación en Edición, Cultura y Comunicación: el campo editorial y las industrias culturales. Buenos Aires: Facultad de Filosofía y Letras de la UBA.
Vicente, RM, Marín, D y Cepeda, O (2018). Análisis de materiales didácticos musicales para Primaria en la escuela digital. Revista Electrónica de LEEME, 42, 1-15.

West, JJ y Bautista, A (2020). Greater than the sum of its parts: promoting systemness in music and arts teacher professional development. Arts Education Policy Review, 122(1), 54-64. 


\section{ANEXO}

\section{Cuestionario "Mini-Deportistas"}

\section{Datos Personales / Informação Pessoal}

1. ¿Dónde vives? Localidad y país. * Onde você mora? Localidade e país.

2. ¿Qué edad tienes? * Quantos anos você tem?

3. ¿Cuál es tu género? * Qual é o seu sexo?

Femenino * Feminino Masculino

4. ¿Cuál es tu profesión? * Qual é a sua profissão?

- Maestro generalista * Pedagogo

- Maestro de música * Professor de música

- Profesor de música en Secundaria y Bachillerato * Professor de música no ensino médio e bacharelado

- Profesor en escuela de música * Professor de escola de música

- Profesor en conservatorio * Professor de conservatório

- Profesor de Universidad * Professor universitário

- Musicoterapeuta * Musicoterapeuta

- Otros * Outros

5. ¿En qué franja de edad trabajas? * Em que faixa etária você trabalha?

- Educación Infantil 0-6 años * Educação infantil 0-6 anos

- Educación primaria 6-12 años * Educação primária 6-12 anos

- Educación Secundaria y Bachillerato * Ensino médio e bacharelado

- Universidad * Universidade

- $\quad$ Adultos

- Otros * Outros

6. ¿Cómo conociste "Mini-Deportistas"? * Como você conheceu os "Mini-Esportistas"?

- $\quad$ Por Internet

- En un curso presencial con los autores * Em um curso presencial com os autores

- A través de un amigo * Através de um amigo

- Otros * Outros

7. ¿Has realizado con anterioridad algún otro curso online? * Você já fez outros cursos on-line?

$$
S i{ }^{*} \operatorname{Sim} N o \text { * Não }
$$

8. Si la respuesta anterior es afirmativa, ¿En qué área de conocimiento? * Se a resposta anterior é afirmativa, em que área do conhecimento?

9. ¿Cuánto tiempo llevas en el curso online "Mini-Deportistas"? * Há quanto tempo você está no curso on-line "Mini-Esportistas"?

10. ¿Cuál fue el motivo por el que escogiste este curso? * Qual foi a razão pela qual você escolheu este curso?

\section{Sobre la plataforma online * Sobre a plataforma online}

11. La plataforma está bien diseñada y organizada por módulos. *A plataforma é bem projetada e organizada por módulos.

- Totalmente de acuerdo * Concordo plenamente

- Algo de acuerdo * Concordo um pouco

- $\quad$ Ni de acuerdo ni en desacuerdo * Não concordo nem discordo

- Algo en desacuerdo * Discordo um pouco

- Totalmente en desacuerdo * Discordo totalmente

12. La plataforma resulta intuitiva y sencilla. * A plataforma é intuitiva e simples.

- Totalmente de acuerdo * Concordo plenamente

- Algo de acuerdo * Concordo um pouco

- Ni de acuerdo ni en desacuerdo * Não concordo nem discordo

- Algo en desacuerdo * Discordo um pouco

- Totalmente en desacuerdo * Discordo totalmente 
13. La plataforma online es una herramienta eficaz para enseñar y aprender contenidos sobre "Música y Movimiento" (ya que dispone de vídeos, músicas, e-books y material gráfico). * A plataforma online é uma ferramenta eficaz para ensinar e aprender conteúdos sobre "Música e Movimento" (já que tem vídeos, música, e-books e material gráfico).

- Totalmente de acuerdo * Concordo plenamente

- $\quad$ Algo de acuerdo * Concordo um pouco

- $\quad$ Ni de acuerdo ni en desacuerdo * Não concordo nem discordo

- Algo en desacuerdo * Discordo um pouco

- Totalmente en desacuerdo * Discordo totalmente

14. Valora del 1 al 5 el grado de utilidad de los diferentes materiales que ofrece el curso (siendo 1 el valor más bajo y 5 el más alto). * Classifique de 1 a 5 o grau de utilidade dos diferentes materiais oferecidos pelo curso ( 1 sendo o valor mais baixo e 50 mais alto).

$$
\text { Vídeos Músicas Material Gráfico E-books }
$$

15. Normalmente entras en la plataforma a través de: * Normalmente você entra na plataforma através de:

- Ordenador * Computador

- Teléfono * Telefone

- Tablet

16. ¿Has tenido algún problema técnico con la plataforma? ${ }^{*}$ Você teve algum problema técnico com a plataforma?

$$
\text { Sí * Sim No * Não }
$$

17. Si la pregunta anterior es afirmativa, valora el grado de eficacia del equipo de soporte para solucionar tu problema. ${ }^{*} \mathrm{Se} a$ pergunta anterior for afirmativa, avalie a eficácia da equipe de suporte na solução do seu problema.
- Excelente
- Muy Bueno * Muito bom
- Bueno * Bom
- Indiferente
- Malo * Ruim

\section{Sobre los autores * Sobre os autores}

18. En tu opinión, los autores muestran dominio en la materia. * Na sua opinião, os autores demonstram domínio do assunto.

- Totalmente de acuerdo * Concordo plenamente

- Algo de acuerdo * Concordo um pouco

- Ni de acuerdo ni en desacuerdo * Não concordo nem discordo

- Algo en desacuerdo * Discordo um pouco

- Totalmente en desacuerdo * Discordo totalmente

19. En tu opinión, los autores se expresan de manera clara. * Na sua opinião, os autores se expressam claramente.

- Totalmente de acuerdo * Concordo plenamente

- Algo de acuerdo * Concordo um pouco

- Ni de acuerdo ni en desacuerdo * Não concordo nem discordo

- Algo en desacuerdo * Discordo um pouco

- Totalmente en desacuerdo * Discordo totalmente

20. Consideras que la metodología utilizada es adecuada. * Você considera que a metodologia utilizada é adequada.

- Totalmente de acuerdo * Concordo plenamente

- $\quad$ Algo de acuerdo * Concordo um pouco

- $\quad$ Ni de acuerdo ni en desacuerdo * Não concordo nem discordo

- Algo en desacuerdo * Discordo um pouco

- Totalmente en desacuerdo * Discordo totalmente

21. Crees que los materiales que presentan y su didáctica son apropiados. * Você acha que os materiais que eles apresentam e sua didática são apropriados.

- Totalmente de acuerdo * Concordo plenamente

- $\quad$ Algo de acuerdo * Concordo um pouco

- Ni de acuerdo ni en desacuerdo * Não concordo nem discordo

- Algo en desacuerdo * Discordo um pouco

- Totalmente en desacuerdo * Discordo totalmente 


\section{Sobre los contenidos del curso * Sobre o conteúdo do curso}

22. Los vídeos de las explicaciónes son útiles para el docente. * Os vídeos das explicações são úteis para o professor.

- Totalmente de acuerdo * Concordo plenamente

- Algo de acuerdo * Concordo um pouco

- Ni de acuerdo ni en desacuerdo * Não concordo nem discordo

- Algo en desacuerdo * Discordo um pouco

- Totalmente en desacuerdo * Discordo totalmente

23. Los vídeos de las actividades te resultan atractivos y adecuados. * Os vídeos das atividades são atraentes e adequados para você.

- Totalmente de acuerdo * Concordo plenamente

- $\quad$ Algo de acuerdo * Concordo um pouco

- Ni de acuerdo ni en desacuerdo * Não concordo nem discordo

- Algo en desacuerdo * Discordo um pouco

- Totalmente en desacuerdo * Discordo totalmente

24. Las actividades propuestas se adecúan a diferentes niveles de dificultad. * As atividades propostas são adaptadas aos diferentes níveis de dificuldade.

- Totalmente de acuerdo * Concordo plenamente

- $\quad$ Algo de acuerdo * Concordo um pouco

- Ni de acuerdo ni en desacuerdo * Não concordo nem discordo

- Algo en desacuerdo * Discordo um pouco

- Totalmente en desacuerdo * Discordo totalmente

25. Las músicas compuestas para este proyecto ayudan a realizar las diferentes actividades propuestas. ${ }^{*}$ A música composta para este projeto ajuda a realizar as diferentes atividades propostas.

- Totalmente de acuerdo * Concordo plenamente

- Algo de acuerdo * Concordo um pouco

- $\quad$ Ni de acuerdo ni en desacuerdo * Não concordo nem discordo

- Algo en desacuerdo * Discordo um pouco

- Totalmente en desacuerdo * Discordo totalmente

26. Los e-books y material gráfico sirven como soporte para entender el planteamiento del curso. * Os e-books e material gráfico servem como suporte para entender a abordagem do curso.

- Totalmente de acuerdo * Concordo plenamente

- Algo de acuerdo * Concordo um pouco

- Ni de acuerdo ni en desacuerdo * Não concordo nem discordo

- Algo en desacuerdo * Discordo um pouco

- Totalmente en desacuerdo * Discordo totalmente

\section{Sobre los usuarios * Sobre usuários}

27. ¿Has podido llevar a cabo hasta el momento algunas actividades del curso? * Você já realizou algumas das atividades do curso até agora?

$$
\text { Sí * Sim No * Não }
$$

28. Si la anterior respuesta es afirmativa ¿Dónde has podido llevar a cabo las actividades? * Se a resposta anterior for afirmativa, onde você conseguiu realizar as atividades?

- En clases presenciales * Nas aulas presenciais

- En clases online * Aulas online

- En casa con la familia * Em casa com a família

- Con amigos * Com amigos

- Otros * Outros

29. ¿Qué actividad funcionó mejor en tu clase? * Qual atividade funcionou melhor na sua aula?

30. Valora el grado de motivación de tus alumnos en referencia al proyecto "Mini-Deportistas". * Avalie o grau de motivação de seus alunos em referência ao projeto "Mini-Esportistas".

- Excelente

- Muy Bueno * Muito bom

- Bueno * Bom

- Indiferente

- Malo * Ruim 
31. Este material, ¿Se corresponde con tu manera de enseñar o es totalmente nuevo para ti? * Este material corresponde à sua maneira de ensinar ou é totalmente novo para você?

- Totalmente nuevo * Totalmente novo

- Se corresponde con mi manera de enseñar * Corresponde à minha maneira de ensinar

- Ni una cosa ni la otra * Nem uma nem a outra

32. Las enseñanzas recibidas, son (o serán) útiles para tu ámbito profesional. * Os ensinamentos recebidos são (ou serão) úteis para a sua área profissional.

- Totalmente de acuerdo * Concordo plenamente

- Algo de acuerdo * Concordo um pouco

- Ni de acuerdo ni en desacuerdo * Não concordo nem discordo

- Algo en desacuerdo * Discordo um pouco

- Totalmente en desacuerdo * Discordo totalmente

33. Este material, te ayuda (o ayudará) a mejorar la planificación de tus clases. * Este material ajuda você (ou ajudará) a melhorar o planejamento de suas aulas.

- Totalmente de acuerdo * Concordo plenamente

- Algo de acuerdo * Concordo um pouco

- $\quad$ Ni de acuerdo ni en desacuerdo * Não concordo nem discordo

- $\quad$ Algo en desacuerdo * Discordo um pouco

- Totalmente en desacuerdo * Discordo totalmente

34. Este material, te ayuda ( 0 ayudará) a hacer la clase más activa, más dinámica. * Este material ajuda você (ou irá ajudá-lo) a tornar a aula mais ativa e dinâmica.

- Totalmente de acuerdo * Concordo plenamente

- $\quad$ Algo de acuerdo * Concordo um pouco

- Ni de acuerdo ni en desacuerdo * Não concordo nem discordo

- $\quad$ Algo en desacuerdo * Discordo um pouco

- Totalmente en desacuerdo * Discordo totalmente

35. El curso online "Mini-Deportistas", te parece un material innovador. * 0 curso on-line de "Mini-Esportistas" parece um material inovador.

- Totalmente de acuerdo * Concordo plenamente

- $\quad$ Algo de acuerdo * Concordo um pouco

- $\quad$ Ni de acuerdo ni en desacuerdo * Não concordo nem discordo

- Algo en desacuerdo * Discordo um pouco

- Totalmente en desacuerdo * Discordo totalmente

36. ¿En qué aspectos te parece más innovador el material de "Mini-Deportistas"? * De que maneira você considera o material "Mini-Esportistas" mais inovador?

37. El proyecto "Mini-Deportistas", te permite trabajar los contenidos de tu programación. *O projeto "Mini-Esportistas" permite que você trabalhe com o conteúdo do seu planejamento.

- Totalmente de acuerdo * Concordo plenamente

- Algo de acuerdo * Concordo um pouco

- Ni de acuerdo ni en desacuerdo * Não concordo nem discordo

- Algo en desacuerdo * Discordo um pouco

- Totalmente en desacuerdo * Discordo totalmente

38. Enumera los principales contenidos que trabajas o crees que trabajarás con tus alumnos a través de "Mini-Deportistas". * Liste os principais conteúdos com os quais trabalha ou pense que trabalhará com seus alunos por meio de "Mini-Esportistas".

39. Este proyecto se puede trabajar de manera interdisciplinar. ${ }^{*}$ Este projeto pode ser trabalhado de maneira interdisciplinar.

- Totalmente de acuerdo * Concordo plenamente

- $\quad$ Algo de acuerdo * Concordo um pouco

- $\quad$ Ni de acuerdo ni en desacuerdo * Não concordo nem discordo

- Algo en desacuerdo * Discordo um pouco

- Totalmente en desacuerdo * Discordo totalmente 
40. El binomio "Música y Movimiento" es esencial para trabajar en la clase de música con alumnos de educación infantil y primaria. * O binômio "Música e Movimento" é essencial para trabalhar na aula de música com alunos do ensino infantil e primário.

- Totalmente de acuerdo * Concordo plenamente

- $\quad$ Algo de acuerdo * Concordo um pouco

- $\quad$ Ni de acuerdo ni en desacuerdo * Não concordo nem discordo

- Algo en desacuerdo * Discordo um pouco

- Totalmente en desacuerdo * Discordo totalmente

41. Valora el grado de satisfacción con el curso online "Mini-Deportistas". * Avalie o grau de satisfação com o curso on-line "MiniEsportistas".

- Excelente

- $\quad$ Muy Bueno * Muito bom

- Bueno * Bom

- Indiferente

- Malo * Ruim

42. ¿Qué aspectos del curso crees que se pueden mejorar (a nivel técnico, pedagógico...)? * Quais aspectos do curso você acha que podem ser aprimorados (em nível técnico, pedagógico ...)?

43. Otras observaciones que quieras aportar: * Outras observações que você deseja contribuir: 